\title{
Electrochemical and Theoretical Studies of Corrosion Inhibition Effect of Durio zibethinus Peel Extract on Copper in the Artificial Seawater
}

\author{
Yuxin Liu ${ }^{1}$, Yuzhe Hu${ }^{1}, H u a H a o^{2, *}$, Xingwen Zheng ${ }^{3}$ \\ ${ }^{1}$ College of Chemistry and Materials Engineering, Beijing Technology and Business University, \\ Beijing 100048, China; \\ ${ }^{2}$ Institute of Chemistry, Chinese Academy of Sciences, Beijing 100190, China; \\ ${ }^{3}$ Key Laboratory of Material Corrosion and Protection of Sichuan Province, Sichuan University of \\ Science \& Engineering, Zigong 643000, China \\ *E-mail: haohuaiccas@126.com
}

Received: 2 December 2021 / Accepted: 10 January 2022 / Published: 2 February 2022

\begin{abstract}
The anticorrosion-active compounds were obtained from Durio zibethinus peel by ethanolic extraction (DZPE), which was experimentally and theoretically evaluated as an efficient corrosion inhibitor for copper in the artificial seawater (ASW). The inhibitory power of DZPE was confirmed by electrochemical and surface analyses. As indicated by potentiodynamic polarization tests, DZPE simultaneously suppressed anodic and cathodic reactions of copper in ASW, and thus yielded the reduced corrosion current density. Results of electrochemical impedance spectroscopy revealed that the charge transfer impedance at copper/solution interface was enhanced in the presence and with the augment of DZPE in ASW along with the improved surface passivation. By virtue of the interfacial adsorption, a well-protected morphology was observed for the copper after immersion in ASW with the optimum dosage of DZPE; and the adsorption of DZPE on copper surface conformed to Langmuir isotherm. Due to the favorable anticorrosion efficacy of DZPE, A largely restrained increase in surface roughness was acquired for the protected specimen as compared to the blank control. Reactive descriptors of the main components in DZPE with divergent chemical states were acquired via firstprinciples calculations under the dominant solvent model, which implied their potential interacting centers toward copper surface. The adsorption mechanism of each component in DZPE on $\mathrm{Cu}$ (110) plane was also revealed by molecular dynamics simulations.
\end{abstract}

Keywords: Durio zibethinus peel; plant extract; green corrosion inhibitor; density functional theory; molecular dynamics simulation 
(C) 2022 The Authors. Published by ESG (www.electrochemsci.org). This article is an open access article distributed under the terms and conditions of the Creative Commons Attribution license (http://creativecommons.org/licenses/by/4.0/). 